\title{
Laju tangkap dan musim penangkapan madidihang (Thunnus albacares) dengan tuna hand line yang didaratkan di Pelabuhan Perikanan Samudera Bitung
}

\author{
Fishing rate and season at hand line caught-Tuna (Thunnus albacares)
} landed in Bitung Oceanic Fisheries Port.

\author{
USEP SETIAWAN*, JOHNY WENNO dan MARIANA E.KAYADOE
}

Program Studi Pemanfaatan Sumberdaya Perikanan, Fakultas Perikanan dan Ilmu Kelautan, Universitas Sam Ratulangi, Manado 95115

\begin{abstract}
Tuna (Thunnus albacares) is a big pelagic fish with an extensive distribution from tropics to subtropics. It is categorized as highly economic fish and takes important role in promoting fisheries trades at the national and international level. This study was aimed at knowing the handline fishing rate and appropriate fishing season. The method used in this study was descriptive through case study approach. The study employed secondary data of Bitung oceanic fisheries port based on 5 year-fisheries log data, from 2011 to 2015. Results showed that the lowest fishing rate occurred in November 2013, $2.24 \mathrm{~kg} / \mathrm{hr} /$ fisher and the highest was found in November 2011, 93.14 $\mathrm{kg} / \mathrm{hr} /$ fisher. Based on fishing season, it was found that fishing season occurred in January, July, August, September, October and November.
\end{abstract}

Keywords : fishing rate, season, tuna

\begin{abstract}
ABSTRAK
Madidihang (Thunnus albacares) merupakan ikan pelagis besar dengan distribusi geografis mulai dari daerah tropis sampai sub tropis. Madidihang tergolong ikan bernilai ekonomis tinggi serta berperan penting dalam menggerakkan perdagangan hasil perikanan secara nasional dan internasional. Penelitian ini bertujuan untuk mengetahui besarnya laju tangkap madidihang dengan tuna hand line dan mengetahui musim yang baik untuk penangkapan madidihang. Metode yang digunakan dalam penelitian ini adalah metode deskriptif dengan pendekatan studi kasus. Data yang digunakan dalam analisis laju tangkap dan musim penangkapan yaitu data sekunder yang di peroleh dari data log perikanan selama 5 tahun (2011-2015) yang tercatat di PPS Bitung. Hasil analisis laju tangkap diperoleh laju tangkap terendah berada pada bulan November 2013 yaitu 2,24 kg/jam/pemancing, sedangkan pada bulan November 2011 memiliki nilai laju tangkap tertinggi yaitu 93,14 kg/jam/pemancing. Berdasarkan hasil analisis musim penangkapan, diketahui bahwa musim penangkapan madidihang terjadi pada bulan Januari, Juli, Agustus, September, Oktober dan Nopember.
\end{abstract}

Kata kunci : Laju tangkap, musim tangkap, madidhang

\section{PENDAHULUAN}

\section{Latar belakang}

Kota Bitung dikenal sebagai kota sentra produksi dan industri perikanan. Sekitar $70 \%$ aktivitas industri di Provinsi Sulawesi Utara terkonsentrasi

\footnotetext{
*Penulis untuk penyuratan; email: usepsetiawan63@yahoo.com
}

di Kota Bitung yang sebagian besar merupakan industri pengolahan ikan yang berorientasi ekspor (Apsari, 2009). Madidihang (Thunnus albacares) merupakan ikan pelagis besar dengan distribusi geografis mulai dari daerah tropis sampai sub tropis. Madidihang tergolong ikan bernilai ekonomis tinggi dan berperan penting dalam menggerakkan perdagangan perikanan secara nasional dan internasional. Kebutuhan dan 
permintaan pasar akan ikan madidihang terus mengalami peningkatan, menyebabkan intensitas penangkapan meningkat di hampir seluruh wilayah perairan Indonesia seperti Teluk Tomini, Laut Maluku, Laut Halmahera, Laut Seram, dan Teluk Berau (Kantun, 2012).

Intensitas penangkapan yang semakin meningkat dapat menyebabkan madidihang mengalami tekanan penangkapan yang berakibat pada penurunan produksi. Penurunan produksi dapat terjadi karena tidak adanya pembatasan akses seperti kelebihan kapasitas, kelebihan investasi dan kelebihan penangkapan.

Keberlanjutan usaha perikanan tangkap dapat ditentukan dari besarnya produksi dan keuntungan usaha yang dapat diperoleh, dimana produksi dan keuntungan dipengaruhi oleh laju tangkap dan musim penangkapan.

\section{Tujuan penelitian}

Tujuan penelitian ini yaitu :

1. Untuk mengetahui besarnya laju tangkap madidihang (Thunnus albacares) dengan tuna hand line

2. Untuk mengetahui musim yang baik untuk penangkapan ikan madidihang (Thunnus albacares)

\section{Tempat dan waktu penelitian}

Penelitian dilakukan di Pelabuhan Perikanan Samudera Bitung Provinsi Sulawesi Utara dan berlangsung selama 3 bulan mulai dari bulan Juni sampai dengan Agustus 2016, yang meliputi pengumpulan data dan informasi di pelabuhan.

\section{METODOLOGI PENELITIAN}

\section{Metode penelitian dan pengumpulan data}

Metode yang digunakan dalam penelitian ini adalah metode penelitian deskriptif dengan pendekatan studi kasus. Data yang dikumpulkan dalam penelitian ini yaitu data alat tangkap, operasi penangkapan, daerah penangkapan, lama operasi setiap hari tangkap serta data log selama 5 tahun (2011-2015).

\section{Metode analisis data}

Laju tangkap

Analisis hasil tangkapan dilakukan secara deskriptif, dengan cara mengklasifikasi, mentabulasi dan menginterpretasi data serta disajikan dalam bentuk tabel dan grafik. Analisis laju tangkap menggunakan interpretasi formulasi Shindo dalam Sparred dan Venema (1999) sebagai berikut :

CPUE $=\frac{\text { Catc } h}{\text { effort }}$

Laju tangkap CR $=\frac{C P U E}{\text { Jam }} \times 100$

$C R($ catch rate $)=$ laju tangkap $(\mathrm{kg} / \mathrm{jam} / \mathrm{pemancing})$ catch $=$ hasil tangkapan $(\mathrm{kg})$

effort= upaya penangkapan (jumlah pemancing)

Analisis musim penangkapan

Analisis musim penangkapan ikan madidihang (Thunnus albacares) menggunakan metode persentase rata-rata atau Average Percentage Methods yang didasarkan pada Analisis Runtun Waktu atau Times Series Analysis (Spiegel, 1961). Menurut Uktolseija dalam Lantu (2012), bila tersedia data untuk periode waktu tertentu, maka analisis yang digunakan untuk menduga musim ikan ialah sebagai berikut:

Hitung nilai hasil tangkapan per upaya tangkap $(\mathrm{CPUE}=$ Catch Per Unit Effort $=\mathrm{U})$ per bulan $\left(\mathrm{U}_{\mathrm{i}}\right)$ dan rata-rata bulanan CPUE dalam setahun $(\bar{U})$

$$
X . j=\frac{1}{t} \sum_{i=1}^{t} X_{i j}
$$

$X . j=$ rata-rata hasil tangkapan bulanan selama periode $\mathrm{t}$ tahun

$\sum_{i=1}^{t} X_{i j}=$ produksibulanan pada bulan ke $\mathrm{j}$ tahun ke $\mathrm{i}$

Musim ikan dapat diketahui dengan membandingkan $X . j$ dengan rata-rata tangkapan $(\bar{X})$, dengan ketentuan: $X . j>\bar{X}$, berarti musim ikan dan $X . j<\bar{X}$, berarti tidak musim ikan. Nilai $\bar{X}$ dapat dicari sebagai berikut:

$$
\bar{X}=\frac{1}{n} \sum X_{i j}
$$

Dimana $\mathrm{n}=\sum n i=12$ bulan.

\section{HASIL DAN PEMBAHASAN}

Kapal tuna hand line yang mendaratkan hasil tangkapannya di Pelabuhan Perikanan Samudera Bitung memiliki ukuran, jenis bahan serta kontruksi yang beragam. Ukuran kapal antara 1 GT (Gross Tonnage) sampai 45 GT namun yang 
diamati dalam penelitian ini hanya sampai ukuran 30 GT. Jenis bahan terbuat dari kayu dan fiber glass. Jumlah awak kapal berjumlah enam sampai dua puluh orang tergantung dari ukuran masingmasing kapal. Alat tangkap tuna hand line yang dioperasikan terdiri dari gulungan tali, tali pancing, pemberat, mata pancing, kili-kili dan batu.

Daerah penangkapan kapal tuna hand line yang mendaratkan hasil tangkapannya di Pelabuhan Perikanan Samudera Bitung berada di Laut Maluku dan Laut Sulawesi, namun sebagian besar kapal tuna hand line menangkap madidihang (Thunnus albacares) di Laut Maluku. Selain ikan tuna yang menjadi sasaran utama penangkapan dengan alat tangkap tuna hand line, tertangkap juga jenis ikan lain sebagai hasil tangkapan sampingan seperti cakalang (Katsuwonus pelamis), Black Marlin atau marlin hitam (Makaira indica) dan ikan lemadang (Coryphaena hippurus).

Hasil tangkapan ikan madidihang (Thunnus albacares) selama periode tahun 2011 sampai 2015, tertinggi dicapai pada bulan Juni sebesar $1.068 .194 \mathrm{~kg}$ dan yang terendah pada bulan Februari sebesar $570.584 \mathrm{~kg}$.

\section{Hasil tangkapan per upaya penangkapan (CPUE)}

Data hasil tangkapan dan upaya penangkapan selama 5 tahun (2011-2015) disajikan pada Tabel 1. Upaya penangkapan yang dipakai dalam perhitungan CPUE adalah jumlah pemancing.

Tabel 1. Catch (kg) dan Effort (Jumlah pemancing) madidihang (Thunnus albacares) tahun 2011-2015

\begin{tabular}{lcrrrrrrrrrr}
\hline \multicolumn{1}{c}{ Tahun } & \multicolumn{2}{c}{$\mathbf{2 0 1 1}$} & \multicolumn{2}{c}{$\mathbf{2 0 1 2}$} & \multicolumn{2}{c}{$\mathbf{2 0 1 3}$} & \multicolumn{2}{c}{$\mathbf{2 0 1 4}$} & \multicolumn{2}{c}{$\mathbf{2 0 1 5}$} \\
\hline Bulan & Catch & Effort & Catch & Effort & Catch & Effort & Catch & Effort & Catch & Effort \\
\hline Januari & 180824 & 980 & 129336 & 1042 & 11015 & 918 & 241348 & 1399 & 140347 & 1881 \\
Februari & 119620 & 1541 & 178747 & 1658 & 22076 & 1425 & 141048 & 2262 & 109093 & 2131 \\
Maret & 135606 & 2359 & 190527 & 2431 & 49428 & 2288 & 200489 & 3116 & 88943 & 2125 \\
April & 173478 & 2340 & 200792 & 2478 & 51882 & 2203 & 280190 & 3306 & 97741 & 1869 \\
Mei & 162636 & 2618 & 214141 & 2805 & 61717 & 2431 & 272498 & 3804 & 152115 & 2280 \\
Juni & 249081 & 2946 & 237483 & 3062 & 79110 & 2830 & 419065 & 3976 & 83455 & 2067 \\
Juli & 187572 & 2248 & 162818 & 2065 & 76983 & 2431 & 269724 & 2160 & 155311 & 1889 \\
Agustus & 182394 & 1388 & 124672 & 1409 & 50440 & 1368 & 209507 & 1765 & 41993 & 1102 \\
September & 215042 & 1964 & 158621 & 2216 & 42377 & 1712 & 349864 & 3214 & 77076 & 1129 \\
Oktober & 223512 & 2173 & 193600 & 2412 & 60843 & 1935 & 362968 & 3428 & 100185 & 2681 \\
November & 218230 & 1121 & 185343 & 1963 & 8948 & 1730 & 420521 & 4071 & 111072 & 2175 \\
Desember & 173722 & 2014 & 216109 & 2227 & 27413 & 1801 & 232094 & 3149 & 125493 & 2475 \\
\hline Total & 2221717 & 23692 & 2192189 & 25768 & 542232 & 21622 & 3399316 & 35650 & 1282824 & 23804 \\
\hline
\end{tabular}

Tabel 1, menunjukkan bahwa total tangkapan pada tahun 2011 sebanyak $2.221 .717 \mathrm{~kg}$, menurun pada tahun 2012 dengan total tangkapan $2.192 .189 \mathrm{~kg}$ dan terus menurun pada tahun 2013 dengan total tangkapan 542.232 kg. Pada tahun 2014 hasil tangkapan naik dengan total tangkapan 3.399.316 $\mathrm{kg}$ dan turun lagi pada tahun 2015 dengan total hasil tangkapan $1.282 .824 \mathrm{~kg}$. Upaya penangkapan tahun 2011 sebesar 23.692 naik pada tahun 2012 menjadi 25.768 dan turun pada tahun 2013 menjadi 21.622. Kemudian pada tahun 2014 upaya penangkapan naik menjadi 35.650 dan turun pada tahun 2015 menjadi 23.804 pemancing.

Pada Tabel 2, terlihat bahwa nilai CPUE tetinggi $194,67 \mathrm{~kg} /$ pemancing tercatat pada bulan
November 2011 dan nilai CPUE terendah 5,17 $\mathrm{kg} /$ pemancing tercatat pada bulan November 2013. Analisis hasil tangkapan per unit penangkapan dapat memberikan gambaran tentang naik turunya produksi sumberdaya perikanan, khususnya ikan madidihang (Thunnus albacares).

\section{LajuTangkap}

Tabel 2 selanjutnya di jabarkan ke dalam CPUE per satuan waktu (jam) yang merupakan ukuran untuk laju tangkap. Satuan yang digunakan dalam perhitungan laju tangkap untuk tahun 2011 sampai 2015 yaitu $\mathrm{kg}$ per jam per pemancing selama operasi penangkapan sebagaimana dikemukakan pada Tabel 3 
Tabel 2. CPUE madidihang Tahun 2011-2015

\begin{tabular}{lrrrrl}
\hline & $\mathbf{2 0 1 1}$ & $\mathbf{2 0 1 2}$ & $\mathbf{2 0 1 3}$ & $\mathbf{2 0 1 4}$ & $\mathbf{2 0 1 5}$ \\
\hline Januari & 184,51 & 124,12 & 12,00 & 172,51 & 74,61 \\
Februari & 77,62 & 107,81 & 15,49 & 62,36 & 51,19 \\
Maret & 57,48 & 78,37 & 21,60 & 64,34 & 41,86 \\
April & 74,14 & 81,03 & 23,55 & 84,75 & 52,30 \\
Mei & 62,12 & 76,34 & 25,39 & 71,63 & 66,72 \\
Juni & 84,55 & 77,56 & 27,95 & 105,40 & 40,37 \\
Juli & 83,44 & 78,85 & 31,67 & 124,87 & 82,22 \\
Agustus & 131,41 & 88,48 & 36,87 & 118,70 & 38,11 \\
September & 109,49 & 71,58 & 24,75 & 108,86 & 68,27 \\
Oktober & 102,86 & 80,27 & 31,44 & 105,88 & 37,37 \\
November & 194,67 & 94,42 & 5,17 & 103,30 & 51,07 \\
Desember & 86,26 & 97,04 & 15,22 & 73,70 & 50,70 \\
\hline
\end{tabular}

Tabel 3. Nilai Laju Tangkap Tuna Hand Line kg/ jam/pemancing

\begin{tabular}{lrrrrr}
\hline & $\mathbf{2 0 1 1}$ & $\mathbf{2 0 1 2}$ & $\mathbf{2 0 1 3}$ & $\mathbf{2 0 1 4}$ & $\mathbf{2 0 1 5}$ \\
\hline Januari & 88,28 & 56,42 & 4,96 & 71,29 & 30,83 \\
Februari & 35,28 & 46,67 & 6,12 & 24,65 & 21,15 \\
Maret & 26,13 & 33,93 & 8,54 & 25,43 & 16,55 \\
April & 35,47 & 36,83 & 9,73 & 35,02 & 20,67 \\
Mei & 29,72 & 33,05 & 10,04 & 29,60 & 26,37 \\
Juni & 40,45 & 35,25 & 11,55 & 41,66 & 18,35 \\
Juli & 42,14 & 35,84 & 13,09 & 54,06 & 35,59 \\
Agustus & 66,37 & 42,33 & 15,96 & 49,05 & 17,32 \\
September & 52,39 & 32,54 & 10,23 & 44,98 & 29,55 \\
Oktober & 49,22 & 36,49 & 12,99 & 41,85 & 15,44 \\
November & 93,14 & 42,92 & 2,24 & 40,83 & 21,10 \\
Desember & 41,27 & 44,11 & 6,29 & 30,45 & 20,95 \\
\hline Jumlah & $\mathbf{5 9 9 , 8 7}$ & $\mathbf{4 7 6 , 3 8}$ & $\mathbf{1 1 1 , 7 3}$ & $\mathbf{4 8 8 , 8 7}$ & $\mathbf{2 7 3 , 8 9}$ \\
\hline Rata-rata & $\mathbf{4 9 , 9 9}$ & $\mathbf{3 9 , 7 0}$ & $\mathbf{9 , 3 1}$ & $\mathbf{4 0 , 7 4}$ & $\mathbf{2 2 , 8 2}$ \\
\hline
\end{tabular}

Tabel 3. menunjukan bahwa laju tangkap terendah setiap bulan selama periode lima tahun 2,24 $\mathrm{kg} / \mathrm{jam} /$ pemancing tercatat pada bulan November 2013 sedangkan nilai laju tangkap tertinggi tercatat pada bulan November 2013 dengan nilai $93,14 \mathrm{~kg} / \mathrm{jam} / \mathrm{pemancing}$. Fluktuasi naik turunnya laju tangkap ditentukan oleh keterampilan pemancing dan ketersediaan sumberdaya.

\section{Musim penangkapan}

Musim penangkapan madidihang di Laut Maluku dan Laut Sulawesi diduga dengan didasarkan pada rata-rata hasil tangkapan per satuan upaya penangkapan setiap bulan selama periode waktu lima tahun. Data catch per unit effort ikan madidihang (Thunnus albacares) dan deviasinya disajikan pada Tabel 4. 
Tabel 4. Data catch per unit effort dan deviasinya setiap bulan

\begin{tabular}{lrrrrrrrrrr}
\hline \multirow{2}{*}{ Bulan } & \multicolumn{2}{c}{$\mathbf{2 0 1 1}$} & \multicolumn{2}{c}{$\mathbf{2 0 1 2}$} & \multicolumn{2}{c}{$\mathbf{2 0 1 3}$} & \multicolumn{2}{c}{$\mathbf{2 0 1 4}$} & \multicolumn{2}{c}{$\mathbf{2 0 1 5}$} \\
\cline { 2 - 11 } & CPUE & Selisih & \multicolumn{1}{c}{ CPUE } & Selisih & CPUE & Selisih & CPUE & Selisih & CPUE & Selisih \\
\hline Januari & 184,51 & 80,46 & 124,12 & 36,13 & 12,00 & $-10,59$ & 172,51 & 72,82 & 74,61 & 20,04 \\
Februari & 77,62 & $-26,43$ & 107,81 & 19,82 & 15,49 & $-7,10$ & 62,36 & $-37,33$ & 51,19 & $-3,38$ \\
Maret & 57,48 & $-46,57$ & 78,37 & $-9,62$ & 21,60 & $-0,99$ & 64,34 & $-35,35$ & 41,86 & $-12,71$ \\
April & 74,14 & $-29,91$ & 81,03 & $-6,96$ & 23,55 & 0,96 & 84,75 & $-14,94$ & 52,30 & $-2,27$ \\
Mei & 62,12 & $-41,93$ & 76,34 & $-11,65$ & 25,39 & 2,80 & 71,63 & $-28,06$ & 66,72 & 12,15 \\
Juni & 84,55 & $-19,50$ & 77,56 & $-10,43$ & 27,95 & 5,36 & 105,40 & 5,71 & 40,37 & $-14,20$ \\
Juli & 83,44 & $-20,61$ & 78,85 & $-9,14$ & 31,67 & 9,08 & 124,87 & 25,18 & 82,22 & 27,65 \\
Agustus & 131,41 & 27,36 & 88,48 & 0,49 & 36,87 & 14,28 & 118,70 & 19,01 & 38,11 & $-16,46$ \\
September & 109,49 & 5,44 & 71,58 & $-16,41$ & 24,75 & 2,16 & 108,86 & 9,17 & 68,27 & 13,70 \\
Oktober & 102,86 & $-1,19$ & 80,27 & $-7,72$ & 31,44 & 8,85 & 105,88 & 6,19 & 37,37 & $-17,20$ \\
November & 194,67 & 90,62 & 94,42 & 6,43 & 5,17 & $-17,42$ & 103,30 & 3,61 & 51,07 & $-3,50$ \\
Desember & 86,26 & $-17,79$ & 97,04 & 9,05 & 15,22 & $-7,37$ & 73,70 & $-25,99$ & 50,70 & $-3,87$ \\
\hline Total & $\mathbf{1 2 4 8 , 5 5}$ & - & $\mathbf{1 0 5 5 , 8 7}$ & - & $\mathbf{2 7 1 , 1 0}$ & - & $\mathbf{1 1 9 6 , 3 0}$ & - & $\mathbf{6 5 4 , 7 9}$ & - \\
Rataan & $\mathbf{1 0 4 , 0 5}$ & - & $\mathbf{8 7 , 9 9}$ & - & $\mathbf{2 2 , 5 9}$ & - & $\mathbf{9 9 , 6 9}$ & - & $\mathbf{5 4 , 5 7}$ & - \\
\hline
\end{tabular}

Tabel 4 menunjukkan bahwa nilai positif pada selisih merupakan waktu penangkapan yang baik atau disebutkan sebagai musim penangkapan. Dengan demikian maka pada tahun 2011 terdapat 4 bulan musim penangkapan madidihang yaitu pada bulan Januari, Agustus, September dan November. Tahun 2012 musim penangkapan madidihang terjadi pada bulan Januari, Februari, Agustus, November dan Desember. Tahun 2013 terdapat 7 bulan musim penangkapan madidihang yaitu bulan April-Oktober. Tahun 2014 musim penangkapan madidihang terjadi pada bulan Januari, Juni, Juli, Agustus, September, Oktober dan November. Tahun 2015 ada 4 bulan musim penangkapan madidihang yaitu bulan Januari, Mei, Juli dan September. Keadaan ini memperlihatkan bahwa musim ikan tidak tetap setiap tahunnya tetapi bergeser secara tidak beraturan. Grafik musim ikan madidihang (Thunnus albacares) disajikan pada Gambar 1 sampai dengan Gambar 6.

Gambar 1 menunjukan bahwa musim tangkap ikan madidihang (Thunnus albacares) terjadi pada bulan Januari, Agustus, September dan November. Sedangkan pada bulan Februari, Maret, April, Mei, Juni, Juli, Oktober dan Desember bukan musim penangkapan madidihang.

Gambar 2 menunjukan bahwa musim penangkapan madidihang (Thunnus albacares) terjadi pada bulan Januari, Februari, Agustus, November dan Desember. Sedangkan bulan Maret,
April, Mei, Juni, Juli, September dan Oktober bukan musim penangkapan madidihang.

Gambar 3 menunjukkan bahwa musim penangkapan madidihang (Thunnus albacares) terjadi pada bulan April, Mei, Juni, Juli, Agustus, September dan Oktober. Sedangkan bulan Januari, Februari, Maret, November dan Desember bukan musim penangkapan ikan madidihang (Thunnus albacares).

Gambar 4 menunjukkan bahwa musim penangkapan madidihang (Thunnus albacares) terjadi pada bulan Januari, Juni, Juli, Agustus, September, Oktober dan November. Sedangkan bulan Februari, Maret, April, Mei dan Desember bukan musim penangkapan ikan madidihang.

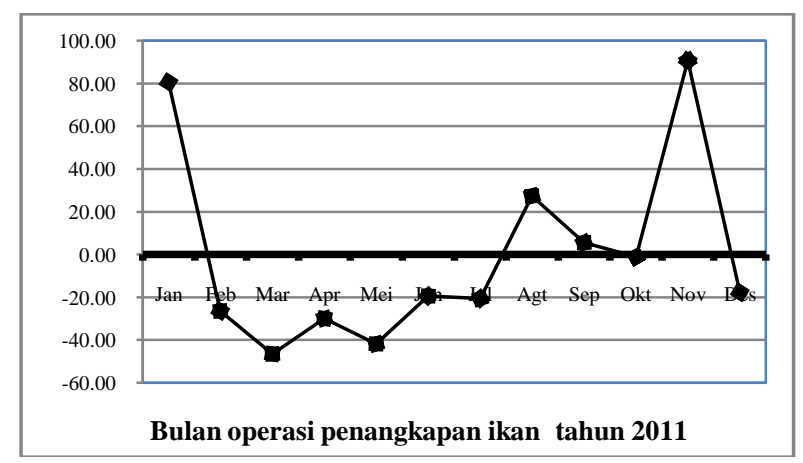

Gambar 1. Musim penangkapan madidihang tahun 2011. 


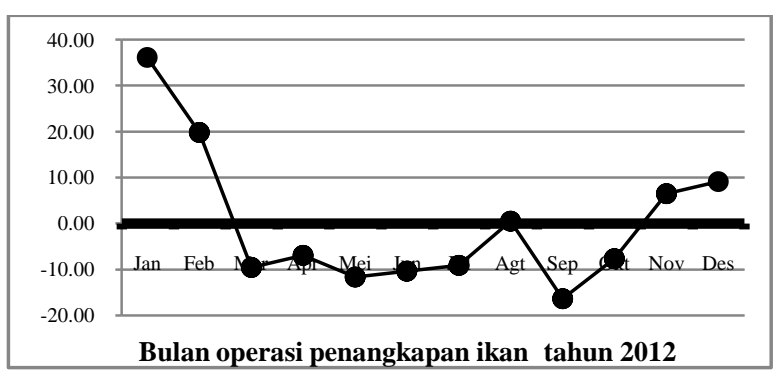

Gambar 2. Musim penangkapan madidihang tahun 2012

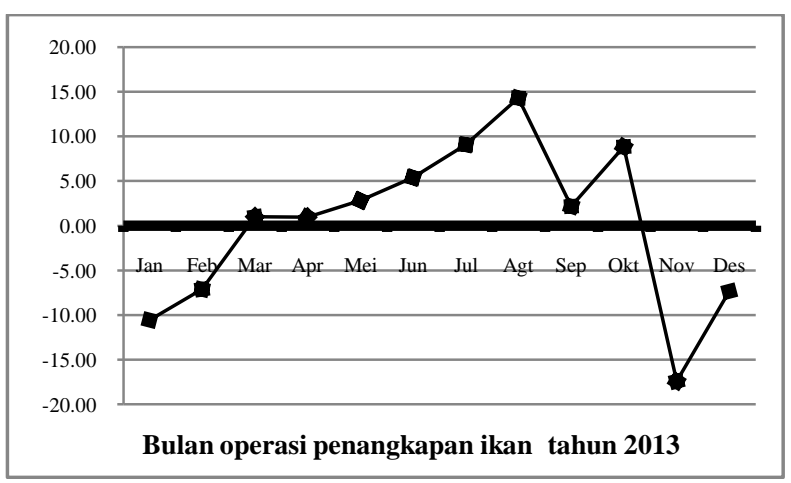

Gambar 3. Musim penangkapan madidihang tahun 2013

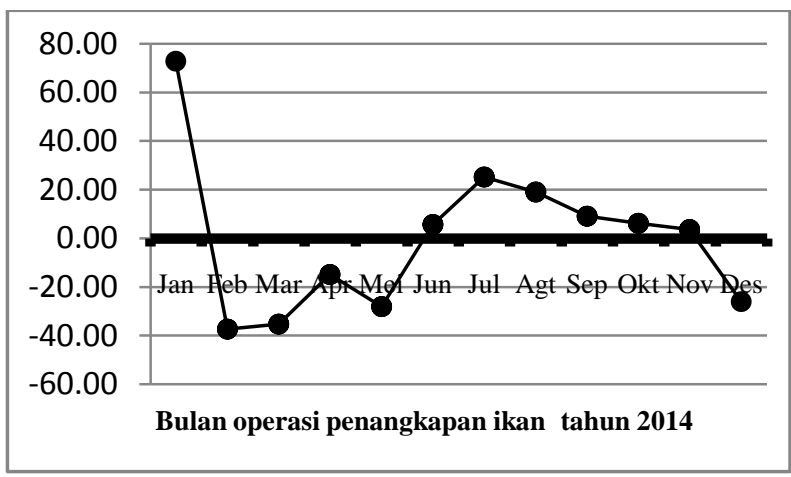

Gambar 4. Musim Penangkapan madidihang tahun 2014

Gambar 5 menunjukkan bahwa musim penangkapan madidihang (Thunnus albacares) terjadi pada bulan Januari, Mei, Juli dan September. Sedangkan bulan Februari, Maret, April, Juni, Agustus, Oktober, November dan Desember bukan musim penangkapan ikan madidihang.

Gambar 6 memperlihatkan bahwa pada tahun 2011 musim tangkap ikan madidihang terjadi pada bulan Januari, Agustus, September dan November. Tahun 2012 musim tangkap madidihang terjadi pada bulan Januari, Februari, Agustus, November dan Desember. Tahun 2013 musim tangkap madidihang terjadi pada bulan Maret, April, Mei,
Juni, Juli, Agustus, September dan Oktober. Tahun 2014 musim tangkap madidihang terjadi pada bulan Januari, Juni, Juli, Agustus, September, Oktober dan November. Tahun 2015 musim tangkap terjadi pada bulan Januari, Mei, Juli,September dan Oktober.

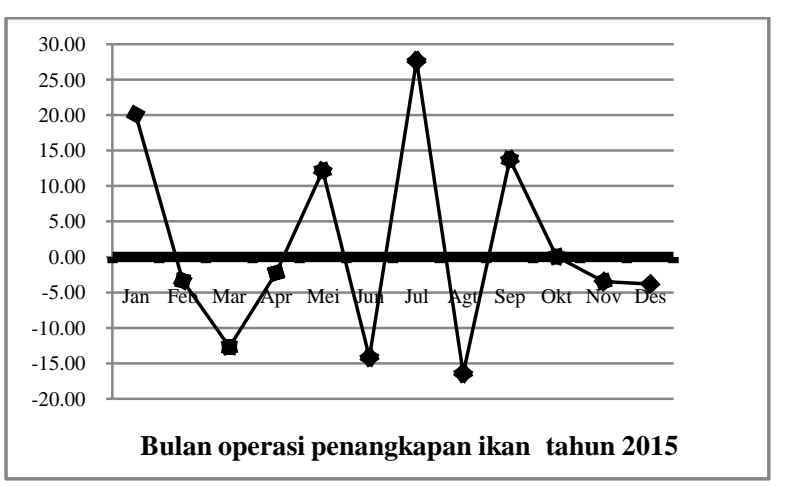

Gambar 5. Musim penangkapan madidihang tahun 2015

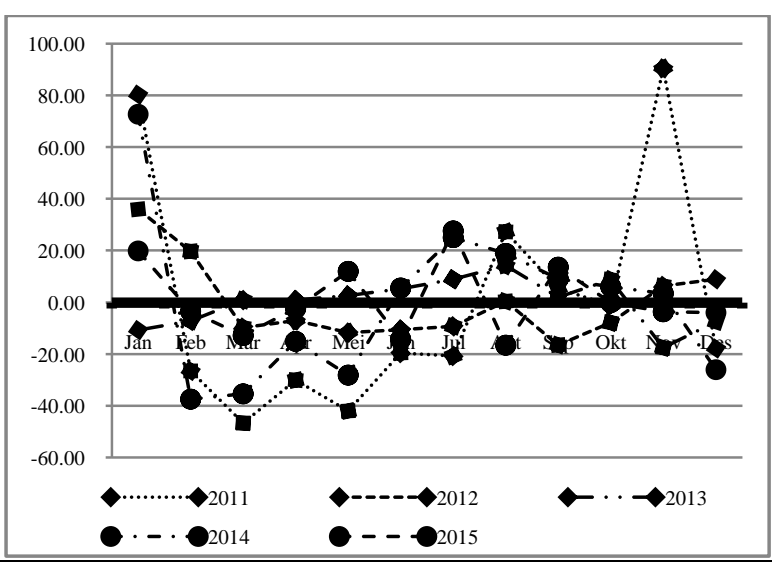

Gambar 6. Musim penangkapan madidihang tahun 20112015

\section{Kesimpulan}

Besarnya laju tangkap tuna hand line terhadap hasil tangkapan madidihang (Thunnus albacares), laju tangkap terendah $2,24 \mathrm{~kg} / \mathrm{jam} /$ pemancing tercatat pada bulan November 2013 sedangkan laju tangkap tertinggi tercatat pada bulan November 2013 dengan 93,14 kg/jam/pemancing. Musim penangkapan madidihang (Thunnus albacares) dengan alat tangkap tuna hand line yang dioperasikan di Laut Maluku dan Laut Sulawesi terjadi pada bulan Januari, Juli, Agustus, September, Oktober dan November. Sedangkan pada bulan Februari, Maret, April, Mei, Juni dan Desember bukan musim penangkapan madidihang. 


\section{Daftar pustaka}

Apsari 2009., dalam Wijaya A.R., 2012 Kontribusi Sub Sektor Perikanan Terhadap Perkembangan Perekonomian Kota Bitung Periode 2000-2007. Fakultas Ekonomi dan Manajemen Institut Pertanian Bogor (IPB). Bogor

Kantun, W., 2012.KondisiStok, Hubungan Kekerabatan dan Keragaman Genetik Tuna Madidihang Thunnus albacores di WPPRI 713 (Selat Makassar, Laut FloresdanTeluk Bone). Disertasi, Program Pascasarjana Universitas Hasanuddin,Makassar.

Labaro, I.L, Katiandagho EM, Reppie E, dan Budiman J. 2008. Pengaruh larutan minyak cumi (Chisabu) terhadap hasil tangkapan pancing ulur tuna di Perairan sekitar pulau Batang Dua. Prosiding Konferensi Nasional VI,Pengelolaan Sumberdaya Pesisir dan Lautan, 2008. ISBN : 978-979-25-2347-8.Hal.782-790

Lantu, J. 2012. Valuasi Perikanan Julung-julung Di Perairan Selat Bangka Kabupaten Minahasa Utara Propinsi Sulawesi Utara. Tesis. Program Pascasarjana.

Universitas Sam Ratulangi. Manado.

P. Sparre, S.C. Venema. Introduksi Pengkajian Stok Ikan Tropis. Pusat Penelitian dan Pengembangan Perikanan. Badan Penelitian dan PengembanganPertanian, FAO, Jakarta, 1999. 